\title{
Does the implementation of a care pathway for patients with hip or knee osteoarthritis lead to fewer diagnostic imaging and referrals by general practitioners? A pre-post-implementation study of claims data
}

Esther H. A. van den Bogaart ${ }^{1 *}$ (D, Mariëlle E. A. L. Kroese ${ }^{1}$, Marieke D. Spreeuwenberg ${ }^{1,2}$, Ramon P. G. Ottenheijm³, Patrick Deckers ${ }^{4}$ and Dirk Ruwaard ${ }^{1}$

\begin{abstract}
Background: The Dutch care for hip and knee osteoarthritis $(\mathrm{OA})$ is of good quality, but there is room for improvement regarding the efficient use of diagnostic imaging and conservative treatment. Therefore a stepped-care approach, in the shape of the care pathway 'Better exercise in osteoarthritis', was implemented to reduce the number of diagnostic imaging requested by GPs and referrals of GPs to orthopaedic care.

Methods: In 2015, the pathway is implemented with the use of educational meetings, distributing guidelines and incorporating reminders in the GPs' referral application. To evaluate the effect of the pathway on the diagnostic and referral behaviour of GPs, hip and knee related health insurance claims are used together with claims of other joints and of a control region for comparison. The average number of claims and the percentage change in the postimplementation period are described. Binary logistic regression analysis is used to examine the interaction between region (intervention and control) and period (pre- and post-implementation). Using random sampling of patient records, information about the practical application of the pathway and the number of hip or knee arthroplasties is added.
\end{abstract}

Results: In both regions, the number of diagnostic imaging decreased and the number of initial orthopaedic consultations increased during the post-implementation period. Significant interaction effects were found in knee-related diagnostics $(p \leq 0.001)$ and diagnostics of other joints $(p=0.039)$. No significant interaction effects were found in hip-related diagnostics $(p=0.060)$ and in initial orthopaedic consultation claims of hip $(p=0.979)$, knee $(p=0.281)$, and other joints $(p=0.464)$. Being referred according to the pathway had no significant effect on the probability of undergoing arthroplasty.

Conclusion: The implementation of the pathway had a positive effect on GPs diagnostic behaviour related to the knee, but not to the hip. The referral behaviour of GPs to orthopaedic care needs attention for future interventions and research, since an increase (instead of a desired decrease) in the number of initial orthopaedic consultations was found. Focusing on the entire width of care for hip and knee OA could be helpful.

Keywords: Care pathway, Stepped care, Osteoarthritis, Diagnostic requests, Referrals, GP, Claims data

\footnotetext{
* Correspondence: e.vandenbogaart@maastrichtuniversity.nl

${ }^{1}$ Department of Health Services Research, Care and Public Health Research Institute (CAPHRI), Faculty of Health Medicine and Life Sciences, Maastricht University, Duboisdomein 30, Maastricht 6229, GT, The Netherlands Full list of author information is available at the end of the article
}

(c) The Author(s). 2019 Open Access This article is distributed under the terms of the Creative Commons Attribution 4.0 International License (http://creativecommons.org/licenses/by/4.0/), which permits unrestricted use, distribution, and reproduction in any medium, provided you give appropriate credit to the original author(s) and the source, provide a link to the Creative Commons license, and indicate if changes were made. The Creative Commons Public Domain Dedication waiver (http://creativecommons.org/publicdomain/zero/1.0/) applies to the data made available in this article, unless otherwise stated. 


\section{Background}

Osteoarthritis (OA) is a common joint disorder affecting more than half of the population aged 65 years and older $[1,2]$. This long-term chronic disease is often associated with stiffness, pain, and functional limitations [3, 4]. Together, this results in a significant reduction in the quality of life of these patients $[5,6]$.

In 2016, an estimated 1.25 million people (around $7 \%$ of the population) had the diagnoses OA in the Netherlands [7]. Annually, there are approximately 140,000 new cases of OA in the country. Knee OA is most common, followed by hip OA. Based on demographic trends, it is expected that the number of people with OA will increase by almost 41\% between 2015 and 2040 [7]. Recent increases in the number of people with obesity, a major determinant of OA, suggests that the prevalence of OA is likely to rise in future [8-10]. In $2015,1.3 \%$ of the total cost of health care in the Netherlands was spent on OA-related care [11]. In view of the increasing prevalence, these costs are likely to rise substantially.

In 2014, the Dutch National Health Care Institute (in Dutch: Zorginstituut Nederland) stated that the care for hip and knee OA in the Netherlands is of good quality, but it also emphasized that there is room for improvement in some areas [12]. One of these suggested improvements is related to the efficient use of diagnostic imaging, such as X-ray or magnetic resonance imaging (MRI). OA is primarily a clinical diagnosis [13]. This implies that in most cases the diagnosis can be based on history taking and physical examination [14, 15]. Despite the recommendations in the guidelines [15], Smink et al. [16] found that general practitioners (GPs) often request for diagnostic imaging.

Another suggestion for improvement is related to the treatment of OA. International evidence-based guidelines for hip and knee OA recommend starting with non-surgical (conservative) treatments [17-21]. Joint replacement surgery (arthroplasty) should be performed only in advanced OA and not in the early stages, given the limited lifespan of prostheses and the less successful outcomes of revision arthroplasty [22-24].

Despite the availability of guidelines, several studies have found that a majority of the patients referred to an orthopaedic surgeon did not receive appropriate prior conservative treatment [25-29]. This can be explained by the lack of practical and clear recommendations and strategies about the necessity and sequence of treatment options [30]. A systematic and period approach, a so-called 'stepped care' strategy, can be a tool to optimise the use of existing conservative treatment options [31, 32]. Stepped care is characterised by interventions that are offered not earlier or with more intensity than necessary. More radical interventions, like hip or knee arthroplasty, should only be considered when patients do not respond sufficiently to conservative treatment options [27, 33].

An example of a stepped care approach is the care pathway 'Better exercise in osteoarthritis' (in Dutch: 'Beter bewegen bij artrose') implemented in the Western Mining District of Limburg, in the South of the Netherlands [34]. Various stakeholders, like GPs, physiotherapists, and an orthopaedic surgeon, are involved in this intervention. The pathway is based on the guideline of the Dutch College of General Practitioners (NHG) [35] and aims to treat patients with knee or hip OA according to a stepped care approach. Furthermore, this pathway clearly states that OA is a clinical diagnosis, and therefore X-rays are not necessary.

The pathway may positively influence quality of care and health outcomes. In addition, unnecessary costs could be avoided by implementing these improvements [12]. The Dutch National Health Care Institute estimated that $90 \%$ of the costs associated with diagnostic imaging related to both hip and knee OA are unnecessary and that with the implementation of the guidelines, more than $€ 14$ million could be saved by deploying conservative treatment [12]. In addition, 5\% of hip arthroplasties and 10\% of knee arthroplasties could be prevented, based on the assumption that a group of patients is already appropriately managed in primary care. This could result in an additional saving of $€ 34$ million [12].

This study aims to evaluate the effect of the implementation of the pathway, on GP diagnostic imaging requests and GP referrals to orthopaedic surgeons for hip and knee OA. In addition, this study evaluates to what extent the pathway is applied in practice before patients are referred to orthopaedic care and the effect of the pathway on the appropriateness of these referrals.

\section{Methods \\ Design}

This is an observational study comparing the diagnostic and referral behaviour of GPs in the pre- and postimplementation period of the intervention using health insurance claims data from 2012 to 2016. In addition, a patient record review is conducted to get more information about the practical application of the pathway and the appropriateness of referrals to orthopaedic care within the intervention region.

\section{Setting}

The pathway originates from a regional collaboration of stakeholders in the Western Mining District located in the South of Limburg. Stakeholders consist of a coordination centre for diagnostics, MCC Omnes; the GP organisation Meditta; Zuyderland Medical Centre (MC) (location Sittard-Geleen); the health insurance company $\mathrm{CZ}$; and a patient representative organisation, Citizen 
Power (in Dutch: Burgerkracht). These organisations work together to provide the right care in the right place [34].

The Western Mining District has a population of about 185,000 people. The population is declining and ageing [36]. The control group incorporated three other regions. These regions are selected because they are located in the same province as the intervention region and are also characterized by a declining and ageing population. Together, these control regions have a population of about 690,000 people.

In the Netherlands, having health insurance is mandatory [37]. In the Western Mining District, $\mathrm{CZ}$ is the health insurance company with the largest market share in the region. In addition, all Dutch residents are registered at a GP practice. Primary care is delivered by GPs, which initiates diagnostics and acts as a gatekeeper to specialised medical care [38]. GP consultations are fully covered by the health insurance [39]. For consulting a medical specialist, a yearly compulsory deductible is levied. This implies that there is a certain amount of specialised medical treatment expenses that a patient has to pay out of pocket before the health insurance company will compensate the expenses. The same applies for diagnostic tests (including diagnostic imaging) and pharmaceuticals prescribed by GPs. The amount of the deductible is determined by the Dutch government and changes every year [40]. During the study period (20122016), the amount increased from $€ 220$ to $€ 385$.

\section{Intervention}

The pathway is designed, using the national guidelines for hip and knee OA [34], by members of an expert group, consisting of two GPs, a physical therapist, an orthopaedic surgeon, a rheumatologist, a radiologist, a physician assistant and a coordinator of MCC Omnes. In February 2015, the pathway is implemented in the Western Mining District based on three interventions: educational meetings, distribution of the guidelines, and reminders. All interventions are developed and coordinated by members of the expert group and focus on improving the stepped care approach of hip and knee OA treatment, reducing diagnostic imaging requests and reducing referrals to orthopaedic surgeons. The educational meetings consist of one meeting organised for GPs and physiotherapists together at the start of the implementation process, followed by advanced educational courses organised separately for GPs and physiotherapists. The educational meetings focus on recognizing $\mathrm{OA}$ and red flag situations, the content of the pathway and related guidelines, the role of different professionals within the pathway (with emphasis on GPs and physiotherapists) and the application of the pathway in practice, for example by discussing practical cases, patient communication skills training and practicing administering corticosteroid injections. The educational meetings are voluntary and professionals earn medical education credits for their presence. Around $20 \%$ of the GPs in the intervention region attended the first education meeting. In addition, the expert group assumes that the attended GPs spread the content of the meetings among their colleagues within their general practice and that all GPs, affiliated with MCC Omnes, eventually conform to their initiatives. To further support the dissemination of the pathway, a visualisation and explanation of the stepped-care approach are placed at the website of MCC Omnes, and in the newsletter and on the mobile application of MCC Omnes to reach all GPs in the region. In addition, to support GPs in applying the pathway in practice, a reminder pops up in the GPs referral application (called ZorgDomein) when requesting hip or knee related diagnostic imaging or when referring patients with hip or knee related complaints to orthopaedic care. This reminder forces GPs to indicate which steps of the pathway have been followed prior to the request or referral. Hence, all GPs are informed about the pathway through these different channels. The pathway focusses on patients with hip and knee OA diagnosed by their GP based on history taking and physical examination. In cases of rheumatic diseases, previous diagnosis of OA, OA that cannot be explained sufficiently, young age $(<45$ years), prominent polyarthritis (in multiple joints), (familial) psoriasis, or inflammatory bowel disease, patients are excluded from being treated according to the pathway.

Figure 1 shows the stepped care process of the pathway. When patients are diagnosed with OA by their GP and patients are eligible for treatment according to the pathway, the GP provides information about OA and advice about lifestyle. When necessary, analgesics are prescribed. The GP refers the patient, according to the conservative policy, to a physiotherapist and when necessary to a dietitian, psychologist (in case of problems with coping), and/or occupational therapist. The physiotherapist provides more (tailored) information about OA to the patient. In addition, an individual treatment process is started, aimed at reducing pain and functional disorders, combined with an exercise program focussing on guiding patients to a more active lifestyle. Preferably, after approximately 6 months, the GP evaluates the results of the conservative treatment. When complaints reduce, patients are advised to continue with the lifestyle advice. When complaints not reduce, additional analgesics could be prescribed or corticosteroid injections are administered. Finally, patients could be referred to specialised medical care (mostly a referral to an orthopaedic surgeon). 


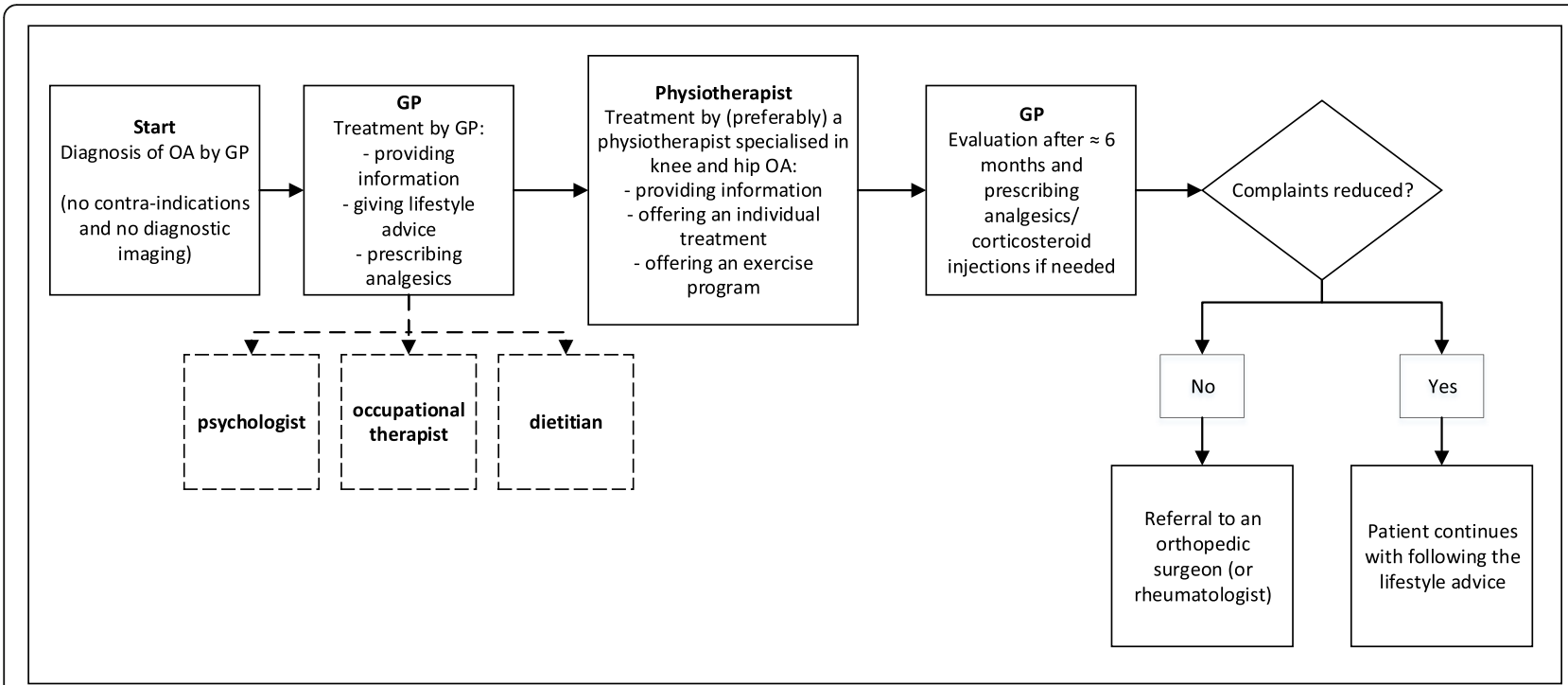

- - (dashed lines) refer to optional steps in the care pathway.

$O A=$ osteoarthritis, $G P=$ general practitioner .

Fig. 1 Process of the stepped care approach in the pathway

\section{Data collection}

\section{Observational study}

The effect of the pathway is assessed using annual health insurance claims data (2012 to 2016) from the health insurance company CZ. Claims data can be categorized as health care administrative data [41]. The health insurance company collects these data for administrative and billing purposes, and they can be used to study health care consumption. The claims data are based on measurements for all $\mathrm{CZ}$ insured persons within the intervention and control region (e.g. census data).

The number of hip- and knee-related claims are compared with claims related to other joints (neck, shoulder, upper arm, elbow, forearm, hand, wrist, fingers, ankle, foot, and toes). Additionally, the number of health insurance claims in the Western Mining District (intervention region) are compared with the number of claims in the control region.

\section{Patient record review}

To collect information about the practical application of the pathway and the appropriateness of referrals to orthopaedic care within the intervention region, a patient record review is conducted using random sampling. Approximately $10 \%$ of the total number of the records of patients with a suspicion of hip or knee OA, who were referred for an initial orthopaedic consultation during the period from February 2015 to October 2016 (post-implementation period), are included.

\section{Outcome measures}

\section{Observational study}

Regarding the claims data, the primary outcome measures are the number of hip- and knee-related diagnostic imaging procedures (X-rays and MRIs) requested by GPs and the number of GP referrals to orthopaedic care per 1000 insured persons.

Based on the claims data, it is not possible to determine the total number of GP referrals to orthopaedic care, due to a lack of follow-up of the referral or nonattendance [42]. Therefore, the actual claims of initial orthopaedic consultations related to OA of the hip and knee and other joints are used, both in the intervention and control region. Initial consultations are recognized by the so-called Diagnosis Treatment Combination (DTC) (in Dutch: Diagnose Behandel Combinatie, DBC) [43]. Every DTC has a unique performance code that includes all information about the type of care (initial or follow-up), the demand for care, the diagnosis and type of treatment.

The characteristics of the entire population insured by $\mathrm{CZ}$ in the intervention region and the control region are 1) the number of insured persons, presented with averages per period, 2) gender distribution, presented using the percentages of men, and 3) average age, presented with means and standard deviations (SDs).

The pre- and post-implementation period is determined by the implementation of the pathway in the beginning of 2015. Therefore, the pre-implementation period is determined as January 2012 to December 2014 and the post-implementation period is determined as January 2015 to December 2016. A post-implementation period of $2 \mathrm{yrs}$ is selected. It is not possible to select a period of 3 yrs due to the delay in the processing of the claims data by the health insurer. 


\section{Patient record review}

The collected patient records using the random sampling contain the answers to the questions related to the reminder that pops-up in the GPs' referral application when they refer patients to orthopaedic care ("Did you (the GP) went through the steps of the pathway?"). The answers to this question (yes or no) are used to check whether patients had been referred according to the pathway. Furthermore, the patients' records contain information about the follow-up orthopaedic care in the hospital. Information about the diagnosis (yes/no OA) and the treatment (yes/no arthroplasty) are collected from these records to check if the referral was appropriate.

\section{Analysis}

\section{Observational study}

Characteristics of the intervention and control region during the pre- and post-implementation period are presented. In addition, the average number of health insurance claims for diagnostic imaging and initial orthopaedic consultations (separately for hip, knee, and other joints) per 1000 insured persons in the pre- and post-implementation period of both regions are reported. The percentage change in the number of requested diagnostic imaging and initial orthopaedic consultations in the post-implementation period compared to the pre-implementation period is calculated and presented. Furthermore, the proportion of diagnostic imaging and initial orthopaedic consultations claims per 1000 insured persons per region and per period are dichotomised to a binary variable (yes/no-claimed diagnostic imaging or initial orthopaedic consultation).

Binary logistic regression analyses are used to determine the influence of the implementation of the pathway on the proportion of health insurance claims for diagnostic imaging and initial orthopaedic consultations per 1000 insured persons in the intervention region compared to the control region. The dependent variable in these models is the binary variable indicating claimed diagnostic imaging (yes/no) or claimed initial orthopaedic consultation (yes/no). The independent variables are region (intervention or control region) and period (pre- or post-implementation period) and the interactions between those variables. The Enter method is used [44]. In addition, odds ratios (OR), $p$-values, and 95\% confidence intervals $(\mathrm{CI})$ are reported.

\section{Patient record review}

The number and percentage of patients referred to orthopaedic care according to the pathway, the number and percentage of patients diagnosed with $\mathrm{OA}$ as determined by the orthopaedic surgeon and the number and percentage of arthroplasties performed are presented in flow charts, separately for patients with a suspicion of hip and knee OA. Pearson's chi-square test is used to test the difference in the probability of undergoing arthroplasty between patients who were referred according to the pathway and patients who were not, again separately for patients with hip and knee OA.

Descriptive statistics and analyses are performed using SPSS version 25, and statistical significance is defined as $p<0.05$ (IBM SPSS Statistics, Armonk, NY).

\section{Expert meetings}

The process of the pathway and results of the analyses are discussed during meetings with the expert group. The purpose of these meeting is to verify the findings and to contribute to a better interpretation of the results.

\section{Results \\ Observational study}

Table 1 shows that the number of insured persons decreased over time in the intervention region. In the control region, the number of insured persons increased. However, the proportions of men and the mean age remained stable over time in both regions. Therefore, it is assumed that the effect of the decrease in the intervention region is limited.

The number of claims and the percentage change in the intervention and control region are described (Table 2). In both regions, the average number of requested diagnostic imaging procedures decreased during the post-implementation period. Regarding the initial orthopaedic consultations, an increase of claims during the post-implementation period in both regions is visible.

As presented in Table 3, there was no statistically significant difference in the decrease of the number of GPrequested hip-related diagnostic imaging during the postimplementation period $(\mathrm{OR}=0.903,95 \% \mathrm{CI}=0.812-1.004$, $p=0.060)$ in the intervention region compared to the control region. However, during the post-implementation period the number of GP-requested knee-related diagnostic imaging $(\mathrm{OR}=0.781,95 \% \mathrm{CI}=0.693-0.880, p \leq 0.001)$ and GPrequested diagnostic imaging of other joints $(\mathrm{OR}=0.931$, 95\% CI $=0.870-0.997, p=0.039$ ) declined statistically significantly more in the intervention region.

Moreover, there was no statistically significant difference in the increase of the number of initial orthopaedic consultation claims of the hip $(\mathrm{OR}=1.002,95 \% \mathrm{CI}=0.871-1.152$, $\mathrm{p}=0.979)$, knee $(\mathrm{OR}=0.894,95 \% \mathrm{CI}=0.728-1.097, \mathrm{p}=$ $0.281)$, or other joints $(\mathrm{OR}=1.091,95 \% \mathrm{CI}=0.864-1.378$, $\mathrm{p}=0.464$ ) in the intervention region compared to the control region (Table 4). 
Table 1 Characteristics of intervention and control region

\begin{tabular}{|c|c|c|c|}
\hline Region and period & Average number of insured persons (N) & Gender - male (\%) & Age in years (mean $\pm S D)$ \\
\hline \multicolumn{4}{|l|}{ Intervention region } \\
\hline Pre & 85,749 & 48.3 & $45.92 \pm 23.26$ \\
\hline Post & 80,078 & 48.4 & $46.36 \pm 23.40$ \\
\hline \multicolumn{4}{|l|}{ Control region } \\
\hline Pre & 295,796 & 48.9 & $45.32 \pm 23.26$ \\
\hline Post & 299,306 & 48.8 & $45.78 \pm 23.39$ \\
\hline
\end{tabular}

\section{Patient record review}

Figures 2 and 3 show the number and percentage of patients referred by their GP (from the intervention region) to orthopaedic care with a suspicion of hip or knee OA and the number of performed arthroplasties. Figure 2 shows that the majority of patients with a suspicion of hip OA (56.7\%) were referred according to the pathway. After the referral, $68.6 \%$ of the patients who were referred according to the pathway were diagnosed with OA. For patients not referred according to the pathway, this percentage was $56.4 \%$. Finally, the percentage of patients who underwent arthroplasty was lower for patients referred according to the pathway than for patients not referred according to the pathway (35.3 and 38.5\%, respectively). In addition, Fig. 3 shows that the majority of patients with a suspicion of knee OA (53.8\%) were referred according to the pathway. After the referral, $75.8 \%$ of the patients who were referred according to the pathway were diagnosed with OA. For patients not referred according to the pathway, this percentage was $59.0 \%$. Finally, the percentage of patients who underwent arthroplasty was higher for patients referred according to the pathway than for patients not referred according to the pathway (39.6 and $28.2 \%$, respectively).

Table 5 shows that for both patients with a suspicion of hip and knee OA, the probability of undergoing arthroplasty does not significantly differ for patients who were or were not referred according to the pathway.

\section{Discussion}

The present study found a significant decrease during the post-implementation period in the number of knee-related diagnostic claims per 1000 insured persons in the intervention region compared to the control region. A similar decrease in the number of requested diagnostic imaging procedures for other joints was found. This decrease indicates that the implementation of the pathway went beyond awareness of requesting hip- and knee-related diagnostic imaging by GPs and positively influenced the GPs when it came to requesting diagnostic imaging in general. No differences in the number of hip-related diagnostic imaging procedures was found between the intervention and control region during the post-implementation period. Additionally, the pathway seems to have less effect on the referral

Table 2 Number of claims per region in the pre- and post-implementation period

\begin{tabular}{|c|c|c|c|c|c|c|}
\hline & \multicolumn{2}{|c|}{ Requested diagnostic imaging } & \multirow[b]{3}{*}{$\begin{array}{l}\text { Percentage } \\
\text { change }(\%) *\end{array}$} & \multicolumn{2}{|c|}{ Initial orthopaedic consultation } & \multirow[b]{3}{*}{$\begin{array}{l}\text { Percentage } \\
\text { change }(\%) *\end{array}$} \\
\hline & Pre & Post & & Pre & Post & \\
\hline & $\begin{array}{l}\text { Average per } 1000 \\
\text { insured persons }(\mathrm{N})\end{array}$ & $\begin{array}{l}\text { Average per } 1000 \\
\text { insured persons }(\mathrm{N})\end{array}$ & & $\begin{array}{l}\text { Average per } 1000 \\
\text { insured persons }(\mathrm{N})\end{array}$ & $\begin{array}{l}\text { Average per } 1000 \\
\text { insured persons }(\mathrm{N})\end{array}$ & \\
\hline \multicolumn{7}{|c|}{ Intervention region } \\
\hline $\begin{array}{l}\text { Hip- } \\
\text { related }\end{array}$ & 15.19 & 13.45 & -11.5 & 10.92 & 13.14 & +20.3 \\
\hline $\begin{array}{l}\text { Knee- } \\
\text { related }\end{array}$ & 12.72 & 9.51 & -25.2 & 5.93 & 6.47 & +9.1 \\
\hline $\begin{array}{l}\text { Other } \\
\text { joints }\end{array}$ & 35.45 & 32.14 & -9.3 & 3.07 & 3.60 & +17.3 \\
\hline \multicolumn{7}{|c|}{ Control region } \\
\hline $\begin{array}{l}\text { Hip- } \\
\text { related }\end{array}$ & 15.94 & 15.43 & -3.2 & 11.30 & 13.50 & +19.5 \\
\hline $\begin{array}{l}\text { Knee- } \\
\text { related }\end{array}$ & 13.24 & 12.91 & -2.5 & 5.37 & 6.77 & +26.1 \\
\hline $\begin{array}{l}\text { Other } \\
\text { joints }\end{array}$ & 43.95 & 43.73 & -0.5 & 5.04 & 5.34 & +6.0 \\
\hline
\end{tabular}

* - = percentage change is negative (a decrease), and += percentage change is positive (an increase) 
Table 3 Results of the logistic regression analysis for claimed diagnostic imaging

\begin{tabular}{|c|c|c|c|c|}
\hline & \multirow{2}{*}{$\begin{array}{l}\text { Odds } \\
\text { Ratio }\end{array}$} & \multirow[t]{2}{*}{ P-value } & \multicolumn{2}{|c|}{ 95\% Confidence Interval } \\
\hline & & & Lower Bound & Upper Bound \\
\hline \multicolumn{5}{|l|}{ Hip-related } \\
\hline Period & 0.981 & 0.573 & 0.916 & 1.050 \\
\hline Region & 0.895 & $0.003 *$ & 0.832 & 0.963 \\
\hline Region $\mathrm{x}$ period & 0.903 & 0.060 & 0.812 & 1.004 \\
\hline \multicolumn{5}{|l|}{ Knee-related } \\
\hline Period & 0.955 & 0.225 & 0.886 & 1.029 \\
\hline Region & 0.898 & $0.008 *$ & 0.829 & 0.973 \\
\hline Region $\mathrm{x}$ period & 0.781 & $0.000 *$ & 0.693 & 0.880 \\
\hline \multicolumn{5}{|l|}{ Other joints } \\
\hline Period & 0.970 & 0.152 & 0.930 & 1.011 \\
\hline Region & 0.764 & $0.000 *$ & 0.729 & 0.801 \\
\hline Region $x$ period & 0.931 & $0.039 *$ & 0.870 & 0.997 \\
\hline
\end{tabular}

${ }^{*} p<0.05$

behaviour of GPs. Regarding to the claims data, a significant difference in the number of initial orthopaedic consultations in the intervention region during the post-implementation period compared to the control region was not found. Furthermore, the random sample of the patient records showed that not all GPs seem to conform to the pathway since almost half of the patients were not referred to orthopaedic care according to the pathway. Besides this, patients with a suspicion of hip or knee OA referred to orthopaedic care according to the pathway had the same probability to undergo arthroplasty than patients referred not according to the pathway. This seems to indicate that the quality of referring did not improve through the implementation of the pathway.

Table 4 Results of the logistic regression analysis for initial orthopaedic consultation claims

\begin{tabular}{|c|c|c|c|c|}
\hline & \multirow{2}{*}{$\begin{array}{l}\text { Odds } \\
\text { Ratio }\end{array}$} & \multirow[t]{2}{*}{ P-value } & \multicolumn{2}{|c|}{ 95\% Confidence Interval } \\
\hline & & & Lower Bound & Upper Bound \\
\hline \multicolumn{5}{|l|}{ Hip-related } \\
\hline Period & 1.103 & $0.039 *$ & 1.005 & 1.209 \\
\hline Region & 0.939 & 0.222 & 0.849 & 1.039 \\
\hline Region $\mathrm{x}$ period & 1.002 & 0.979 & 0.871 & 1.152 \\
\hline \multicolumn{5}{|l|}{ Knee-related } \\
\hline Period & 1.112 & 0.128 & 0.970 & 1.274 \\
\hline Region & 1.015 & 0.844 & 0.877 & 1.173 \\
\hline Region $\mathrm{x}$ period & 0.894 & 0.281 & 0.728 & 1.097 \\
\hline \multicolumn{5}{|l|}{ Other joints } \\
\hline Period & 1.007 & 0.922 & 0.878 & 1.155 \\
\hline Region & 0.600 & $0.000 *$ & 0.509 & 0.709 \\
\hline Region x period & 1.091 & 0.464 & 0.864 & 1.378 \\
\hline
\end{tabular}

${ }^{*} p<0.05$
The results of the present study regarding the absence of a significant decrease in the number of hip related diagnostic imaging are in line with the study of Linsell et al. [45] in which GPs were more likely to request an $\mathrm{x}$-ray for older people with hip pain than for older people with knee pain. A possible explanation for this could be the fact that hip complaints are more complex for GPs to manage. Literature shows that pain from the hip is difficult to define and that it is difficult to determine the exact source of pain $[46,47]$, that hip OA patients have more advanced complaints and that triggers for symptomatic presentation in hip OA are less understood [48]. When GPs experience difficulties in diagnosing hip related complaints, requesting diagnostic imaging can be a strategy to deal with these uncertainties [49]. Therefore, improving GPs skills to set the diagnosis $\mathrm{OA}$ of the hip could be the focus in future educational meetings. In addition, during the expert meetings, GPs revealed that it could be difficult to convince patients that diagnostic imaging is not always necessary to diagnose OA. Previous studies [50-52] have found that GPs' perception of patient pressure influences the non-adherence to guidelines concerning indications for diagnostic imaging, like an X-ray or MRI. Moreover, Baker et al. (2006) found that GPs believed that denying an Xray could adversely affect the doctor-patient relationship. Although patient communication was part of the educational meetings, further improving GPs' patient-centred communication skills can be useful, since these skills are associated with fewer diagnostic testing expenditures [53].

An explanation for the lack of effect found in the present study regarding the referral behaviour of GPs may be the fact that the practical application of the pathway is not optimal since not all patients were referred to orthopaedic care according to the pathway. This could explain why no decreasing effect was found in the number of initial orthopaedic consultation claims. According to Rogers [54], when implementing an innovation, a part of the target group is sceptical and will offer resistance to change behaviour. Therefore, gaining insight into the application of the pathway by GPs may provide valuable information about the non-users. These insights can be used to evaluate barriers for application and to tailor interventions in order to stimulate the practical application [55]. Another explanation for the lack of effect could be the worldwide consistent increase in the incidence of joint arthroplasty [56]. This also explains the similar increase found in the control region. Additionally, during the expert meetings it emerged that patients can have a strong preference for a referral to orthopaedic care. Therefore, a referral sometimes is the only way to let patients accept 


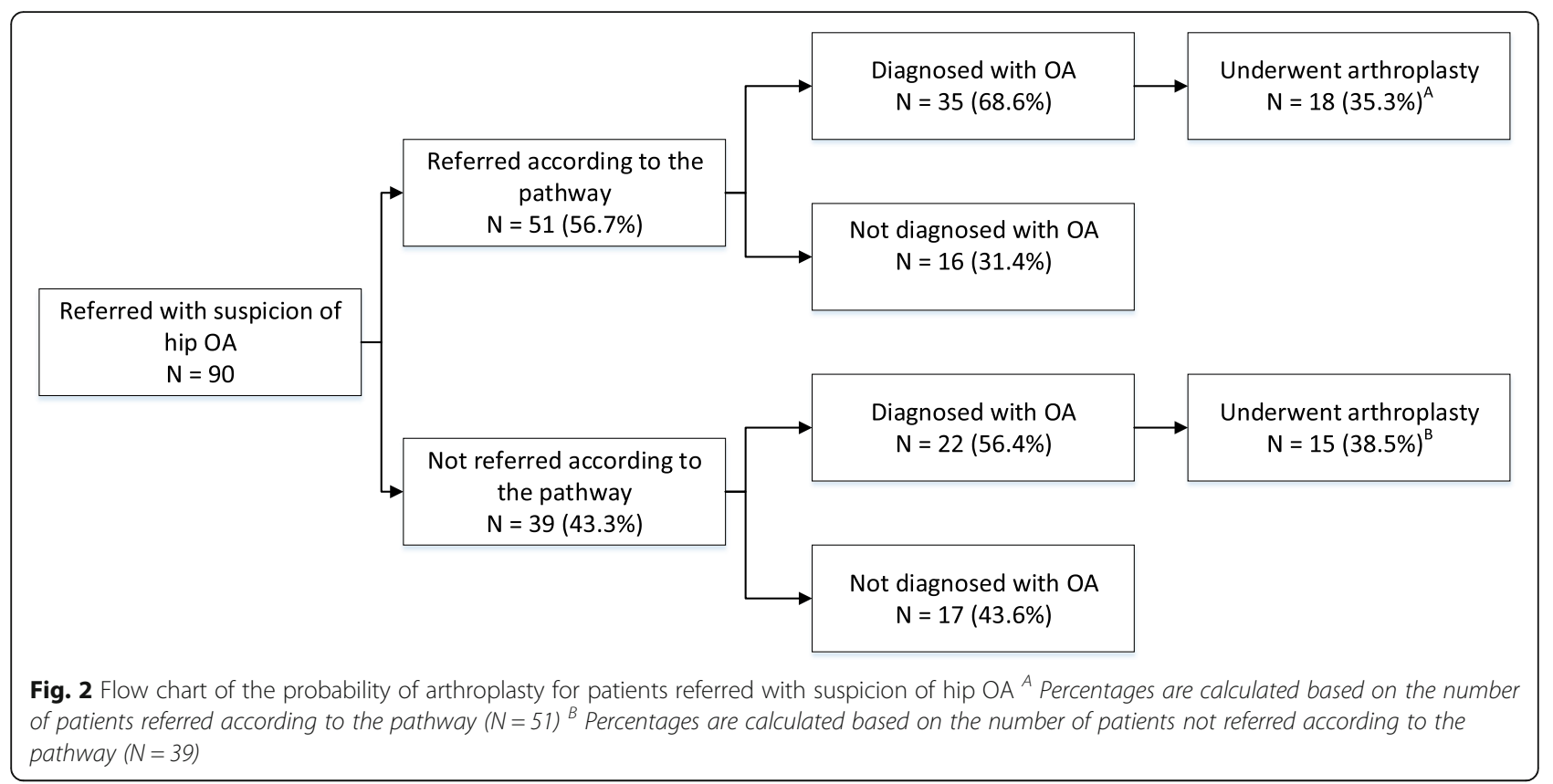

that surgical treatment might not be beneficial. Literature confirms that patients' preferences and GPs' perception of patient pressure indeed influence the GP referral behaviour $[52,57]$. This supports the evidence that guidelines are relatively ineffective when implemented on their own [58-60]. Again, improving patient-centred communication skills can be useful. Furthermore, increasing the consultation time per patient was mentioned during the expert meetings as an important criterion to apply these skills properly. Literature shows that longer consultations are associated with greater patient enablement [61], higher patient-centeredness [62], and a higher degree of offering lifestyle advice and preventive activities [63]. However, evidence about the influence of consultation length on the number of referrals and patient satisfaction is lacking [64]. In addition, exploring other interventions focussing on referring more appropriately to specialised medical care can be beneficial to reduce the inefficient use of limited resources [65-67]. Examples of such interventions are peerreviewing referrals within a general practice before sending them to specialised medical care, enabling GPs to obtain the advice of medical specialists, periodic visits by

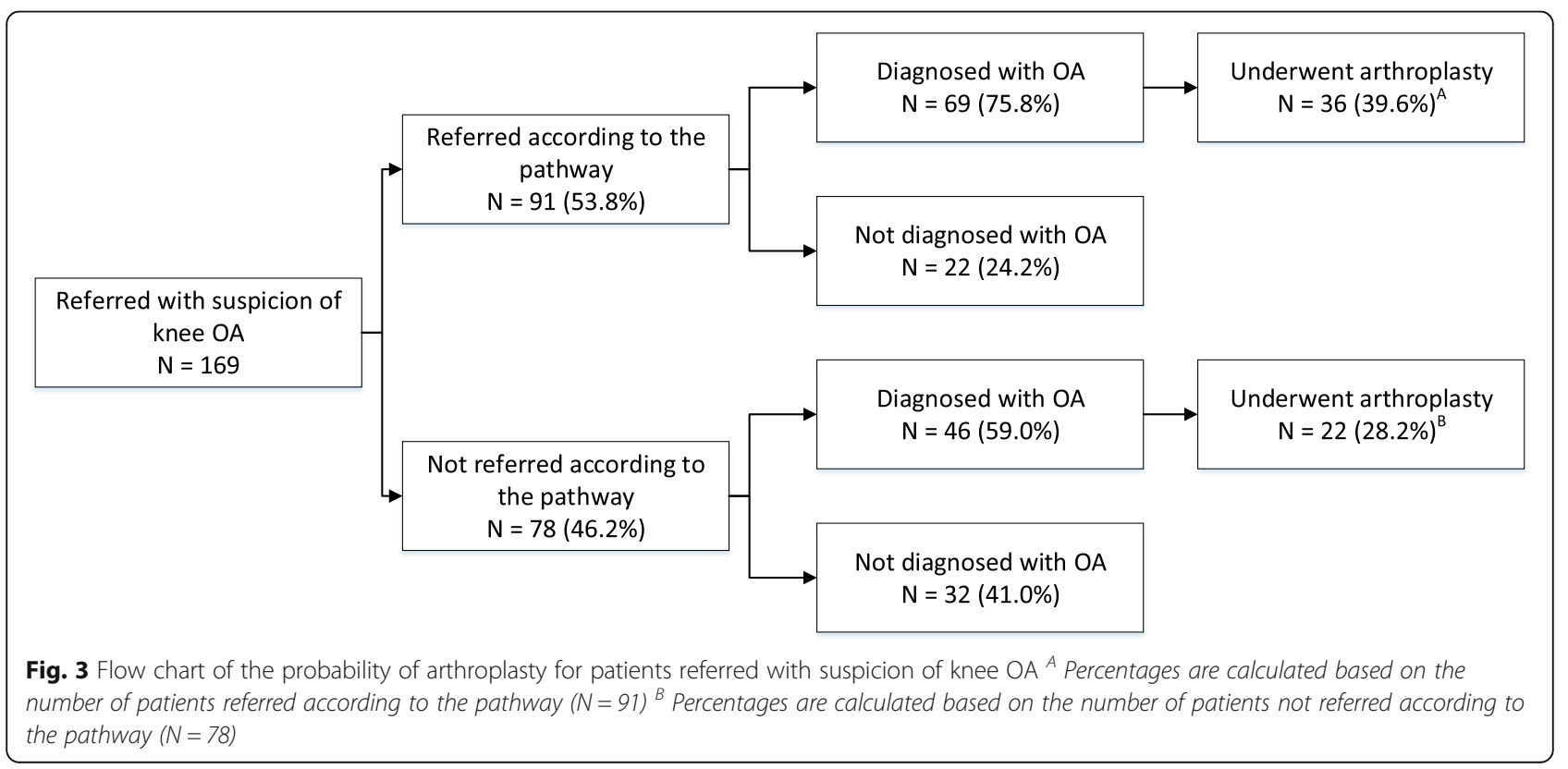


Table 5 Percentages and numbers of arthroplasty in patients being referred or not according to the pathway

\begin{tabular}{llll}
\hline & Total & Arthroplasty \% (N) & No \\
Hip OA & Yes & & P-value ${ }^{a}$ \\
Referred according to the pathway & 90 & $35.3(18)$ & $64.7(33)$ \\
Not referred according to the pathway & 51 & $38.5(15)$ & $61.5(24)$ \\
Knee OA & 39 & & $60.757(55)$ \\
Referred according to the pathway & 169 & $39.6(36)$ & $71.8(56)$ \\
Not referred according to the pathway & 91 & $28.2(22)$ & 0.121 \\
\hline
\end{tabular}

${ }^{a}$ Tested with Pearson's chi-square test

medical specialists to GP practices, and shifts to outpatient clinics in which orthopaedic surgeons or other health-care professionals with a special interest in musculoskeletal problems (for example GPs, nurse practitioners, or physician assistants) provide care in a community setting [67]. These alternatives appear promising with respect to reducing unnecessary referrals to specialised medical care but require further investigation into the effects on quality of care, patients' experiences, and cost of care [67].

Another point of attention mentioned during the expert meetings was the quality of physical therapy. Although the educational meetings and the distribution of the guidelines also aimed at physiotherapists, the focus of this study was on the impact of the implementation of the pathway on GPs behaviour. However, if physiotherapist do not use conservative treatment optimally and patients therefore do not experience improvements, GPs may feel forced to refer patients to orthopaedic care. Therefore, the practical implications of the pathway for physiotherapists and possibly other healthcare professionals (such as dieticians and psychologists) should be addressed in future research.

Based on the results, it is difficult to indicate which intervention (educational meetings, distribution of the guidelines, or reminders) contributed most to the decrease in the number of requested diagnostic imaging procedures related to the knee and other joints since this study did not examined the effect of the different interventions separately. However, in a systematic review conducted by French et al. [68] reminders were mentioned as potentially effective to change health professional behaviour and improve the use of diagnostic imaging. In the same review, educational meetings were not shown to be effective for changing imaging ordering behaviour. Furthermore, Hollingworth et al. [69] found no evidence about the effect of distributing clinical guidelines on changing GPs imaging behaviour related to patients with lumbar spine complaints. In addition, according to the literature [70], the educational meetings organised by members of the expert group have potential to impact on referral rates. More research is needed to learn about the effects of the various interventions within the context of this pathway. This information is needed to further optimise the implementation of the pathway and to achieve a further increase in the appropriate use of diagnostic imaging and possibly achieve a decrease in the number of referrals to orthopaedic care.

\section{Limitations}

In the present study, annual claims data were used. To ensure anonymity, only aggregated data (number of claims per year) were available and no analysis at an individual level could be made. Furthermore, claims data from only one health insurance company were used, which limits the ability to generalise the results of the study to a wider population (external validity) [71]. Since data from the health insurance company with the largest market share in the region were used, problems of selection bias are limited.

In addition, data on the exact extent to which the pathway was applied at GP level in the intervention region were missing. Although all GPs were informed about the pathway, information about how many GPs requested diagnostic imaging procedures and referred patients to orthopaedic care according to the guidelines was lacking. This makes it difficult to attribute the implementation results of the pathway and to consider if there is more room for improvement. Therefore, more research is needed to measure the "real" effect of the pathway in the future.

Furthermore, the present study focused merely on the effects of the implementation of the pathway on GPs behaviour. However, healthcare professionals like physiotherapists, dieticians and psychologist are also involved in the conservative treatment of patients with hip and knee OA. Therefore, research on the effects of the pathway across the entire width of care for hip and knee OA is necessary in order to improve the effect of the pathway.

Finally, it is important to focus not only on the number of requested diagnostic imaging procedures and referrals to orthopaedic care, but also on the effect of the pathway 
on patient satisfaction, quality and costs of care [72]. Therefore, more extensive research in patients, for example through the use of questionnaires, is needed [73].

\section{Conclusion}

The introduction of a pathway aiming to reduce GP diagnostic imaging requests and GP referrals to orthopaedic surgeons for hip and knee OA, had mixed effects. Results showed a decrease in the number of diagnostic imaging requests for knee and other joint related OA, but no impact was found on those for hip OA. In parallel, referrals to orthopaedic care increased during the post-implementation period, both for hip and knee OA related referrals.

Future research is needed to identify the specific role of the interventions in their effectiveness in improving the diagnostic behaviour of GPs, particularly related to diagnostic imaging procedures of the hip. In addition, further research on the referral behaviour of GPs is necessary, which should focus on possible other interventions and the entire width of care for hip, and knee OA in order to improve the effect of the pathway.

\section{Abbreviations}

Cl: Confidence interval; GP: General Practitioner; MC: Medical centre; MRI: Magnetic resonance imaging; NHG: Dutch College of General Practitioners (in Dutch: Nederlands Huisartsen Genootschap);

OA: Osteoarthritis; OR: Odds ratio; SD: Standard deviation

\section{Acknowledgements}

We acknowledge the insurer CZ, especially Daniëlle Baenen and Marian Jacobs, and Zuyderland Medical Centre, especially Tamara Rademakers, for their contributions in providing us with data. Finally, we acknowledge all members of the project group 'Beter Bewegen bij Artrose' of MCC Omnes for their effort.

\section{Availability of data and material}

The data that support the findings of this study are available from the health insurance company CZ and Zuyderland Medical Centre, but restrictions apply to the availability of these data, which were used under license for the current study, and so are not publicly available. Data are however available from the authors upon reasonable request and with the permission of $C Z$ or Zuyderland Medical Centre.

\section{Authors' contributions}

$E B, M K, M S$, and DR designed the study. EB performed the statistical analysis and drafted the manuscript. $\mathrm{RO}$ and PD contributed to the interpretation of the data. MK, MS, RO, PD, and DR read the manuscript and contributed to the critical revision of the manuscript. All authors read and approved the submission of the final draft.

\section{Funding}

For this study funding has been received from the non-profit private health insurers CZ and VGZ (via the cooperative 'Reinforcing Primary Care South of the Netherlands'; in Dutch: Versterking Eerstelijn Zuid-Nederland) and the Province of Limburg, the Netherlands. The funders have no influence on the research; independent researchers conducted the research.

\section{Ethics approval and consent to participate}

This study was submitted to and approved by the Medical Research and Ethics Committee of Zuyderland Medical Centre and Zuyd University of Applied Sciences (Application number: 15-N-123). Data used in this study were already available and patients were not physically involved in the research. In addition, participant consent was not necessary as this study used de-identified data which was obtained as part of evaluation of patient care and which was confirmed by the Medical Research and Ethics Committee. In order to gain access to the data of health insurance company $C Z$, administrative permission was required. Therefore, health insurance company $C Z$ and Maastricht University signed an agreement for data access.

\section{Consent for publication}

Not applicable.

\section{Competing interests}

The authors declare that they have no competing interests.

\section{Author details}

${ }^{1}$ Department of Health Services Research, Care and Public Health Research Institute (CAPHRI), Faculty of Health Medicine and Life Sciences, Maastricht University, Duboisdomein 30, Maastricht 6229, GT, The Netherlands. ${ }^{2}$ Research Centre for Technology in Care, Zuyd University of Applied Sciences, Heerlen, The Netherlands. ${ }^{3}$ Department of Family Medicine, Care and Public Health Research Institute (CAPHRI), Faculty of Health Medicine and Life Sciences, Maastricht University, Maastricht, The Netherlands. ${ }^{4}$ Department of Orthopaedic Surgery, Zuyderland Medical Centre, Sittard-Geleen, the Netherlands.

Received: 5 February 2019 Accepted: 28 October 2019

Published online: 09 November 2019

\section{References}

1. Cross M, Smith E, Hoy D, Nolte S, Ackerman I, Fransen M, et al. The global burden of hip and knee osteoarthritis: estimates from the global burden of disease 2010 study. Ann Rheum Dis. 2014;73(7):1323-30. https://doi.org/10. 1136/annrheumdis-2013-204763.

2. Musumeci G, Szychlinska MA, Mobasheri A. Age-related degeneration of articular cartilage in the pathogenesis of osteoarthritis: molecular markers of senescent chondrocytes. Histol Histopathol. 2015;30(1):1-12. https://doi.org/ 10.14670/hh-30.1.

3. Kaplan W, Wirtz VJ, Mantel-Teeuwisse A, Stolk P, Duthey B, Laing R. Priority medicines for Europe and the world (2013 update). Geneva: World Health Organization; 2013.

4. Neogi T. The epidemiology and impact of pain in osteoarthritis. Osteoarthr Cartil. 2013;21(9):1145-53. https://doi.org/10.1016/j.joca.2013.03.018.

5. Rabenda V, Manette C, Lemmens R, Mariani AM, Struvay N, Reginster JY. Prevalence and impact of osteoarthritis and osteoporosis on health-related quality of life among active subjects. Aging Clin Exp Res. 2007;19(1):55-60.

6. Laslett LL, Quinn SJ, Winzenberg TM, Sanderson K, Cicuttini F, Jones G. A prospective study of the impact of musculoskeletal pain and radiographic osteoarthritis on health related quality of life in community dwelling older people. BMC Musculoskelet Disord. 2012;13:168. https://doi.org/10.1186/ 1471-2474-13-168

7. Volksgezondheidenzorg.info. Osteoarthritis Figures \& Context: Current situation [Artrose Cijfers \& Context: Huidige situatie] 2016a. Available from: https://www.volksgezondheidenzorg.info/onderwerp/artrose/cijfers-context/ huidige-situatie\#node-prevalentie-en-aantal-nieuwe-gevallen-van-artrose.

8. de Mutsert R, den Heijer M, Rabelink TJ, Smit JWA, Romijn JA, Jukema JW, et al. The Netherlands epidemiology of obesity (NEO) study: study design and data collection. Eur J Epidemiol. 2013;28(6):513-23. https://doi.org/10. 1007/s10654-013-9801-3

9. Thijssen E, van Caam A, van der Kraan PM. Obesity and osteoarthritis, more than just wear and tear: pivotal roles for inflamed adipose tissue and dyslipidaemia in obesity-induced osteoarthritis. Rheumatology. 2015;54(4): 588-600. https://doi.org/10.1093/rheumatology/keu464.

10. King LK, March L, Anandacoomarasamy A. Obesity Osteoarthritis. Indian J Med Res. 2013;138(2):185-93.

11. Volksgezondheidenzorg.info. Osteoarthritis: Costs [Artrose: Kosten] $2016 \mathrm{~b}$. Available from: https://www.volksgezondheidenzorg.info/onderwerp/ artrose/kosten/kosten\#node-kosten-van-zorg-naar-vorm-van-artrose.

12. Zorginstituut Nederland. Appropriate care, improving care of knee and hip osteoarthritis [Zinnige zorg, verbetersignalement zorg bij artrose van knie en heup]. Diemen; 2014.

13. Sinusas K. Osteoarthritis: diagnosis and treatment. Am Fam Physician. 2012; 85(1):49-56 
14. Chong T, Don DW, Kao MC, Wong D, Mitra R. The value of physical examination in the diagnosis of hip osteoarthritis. J Back Musculoskelet Rehabil. 2013;26(4):397-400. https://doi.org/10.3233/BMR-130398.

15. Kampshoff CS, Peter WFH, van Doormaal MCM, Knoop J, Meerhoff GA, Vliet Vlieland TPM. The Royal Dutch Society for Physical Therapy (KNGF) Guideline for conservative, pre- and post-operative treatment in patients with Osteoarthritis of the hip and knee. [KNGF-richtlijn Artrose heup-knie. Conservatieve, pre- en postoperatieve behandeling]. Houten: Koninklijk Nederlands Genootschap voor Fysiotherapie (KNGF); 2018.

16. Smink AJ, Bierma-Zeinstra SMA, Schers HJ, Swierstra BA, Kortland JH, Bijlsma JWJ, et al. Non-surgical care in patients with hip or knee osteoarthritis is modestly consistent with a stepped care strategy after its implementation. Int J Qual Health Care. 2014;26(4):490-8. https://doi.org/10.1093/intghc/mzu058.

17. Netherlands Orthopaedic Association (NOV). Guideline diagnostics and treatment of hip- and knee osteoarthritis. Utrecht: Quality Institute for Health Care (CBO); 2007.

18. Fernandes L, Hagen KB, Bij|sma JWJ, Andreassen O, Christensen P, Conaghan PG, et al. EULAR recommendations for the non-pharmacological core management of hip and knee osteoarthritis. Ann Rheum Dis. 2013; 72(7):1125-35. https://doi.org/10.1136/annrheumdis-2012-202745.

19. Conaghan PG, Dickson J, Grant RL, Grp GD. Guidelines - care and management of osteoarthritis in adults: summary of NICE guidance. Br Med J. 2008;336(7642):502-3. https://doi.org/10.1136/bmj.39490.608009.AD.

20. Hochberg MC, Altman RD, April KT, Benkhalti M, Guyatt G, McGowan J, et al. American College of Rheumatology 2012 recommendations for the use of nonpharmacologic and pharmacologic therapies in osteoarthritis of the hand, hip, and knee. Arthritis Care Res (Hoboken). 2012;64(4):465-74.

21. Zhang W, Moskowitz RW, Nuki G, Abramson S, Altman RD, Arden N, et al. OARSI recommendations for the management of hip and knee osteoarthritis, part II: OARSI evidence-based, expert consensus guidelines. Osteoarthr Cartil. 2008;16(2):137-62. https://doi.org/10.1016/j.joca.2007.12.013.

22. Bennell KL, Hunter DJ, Hinman RS. Management of osteoarthritis of the knee. Br Med J. 2012;345:e4934. https://doi.org/10.1136/bmj.e4934.

23. Wiegant $\mathrm{K}$, van Roermund $\mathrm{PM}$, Intema F, Cotofana S, Eckstein F, Mastbergen SC, et al. Sustained clinical and structural benefit after joint distraction in the treatment of severe knee osteoarthritis. Osteoarthr Cartil. 2013;21(11):1660-7. https://doi.org/10.1016/j.joca.2013.08.006.

24. Bayliss LE, Culliford D, Monk AP, Glyn-Jones S, Prieto-Alhambra D, Judge A, et al. The effect of patient age at intervention on risk of implant revision after total replacement of the hip or knee: a population-based cohort study. Lancet. 2017;389(10077):1424-30. https://doi.org/10.1016/S0140-6736(17)30059-4.

25. Shrier I, Feldman DE, Gaudet MC, Rossignol M, Zukor D, Tanzer M, et al. Conservative non-pharmacological treatment options are not frequently used in the management of hip osteoarthritis. J Sci Med Sport. 2006;9(1-2): 81-6. https://doi.org/10.1016/j.jsams.2006.02.002.

26. Hofstede SN, Vlieland TPMV, van den Ende CHM, Nelissen RGHH, Marang-van de Mheen PJ, van Bodegom-Vos L. Variation in use of non-surgical treatments among osteoarthritis patients in orthopaedic practice in the Netherlands. Bmj Open. 2015;5:e009117. https://doi. org/10.1136/bmjopen-2015-009117.

27. Snijders GF, den Broeder AA, van Riel PLCM, Straten VHHP, de Man FHR, van den Hoogen FHJ, et al. Evidence-based tailored conservative treatment of knee and hip osteoarthritis: between knowing and doing. Scand J Rheumatol. 2011;40(3):225-31. https:/doi.org/10.3109/03009742.2010.530611.

28. Dhawan A, Mather RC 3rd, Karas V, Ellman MB, Young BB, Bach BR Jr, et al. An epidemiologic analysis of clinical practice guidelines for non-arthroplasty treatment of osteoarthritis of the knee. Arthroscopy. 2014;30(1):65-71. https://doi.org/10.1016/j.arthro.2013.09.002.

29. DeHaan MN, Guzman J, Bayley MT, Bell MJ. Knee osteoarthritis clinical practice guidelines -- how are we doing? J Rheumatol. 2007;34(10):2099.

30. van den Ende CM, Bierma-Zeinstra SM, Vlieland TP, Swierstra BA, Voorn TB, Dekker J. Conservative treatment of hip and knee osteoarthritis: a systematic, step-by-step treatment strategy. Ned Tijdschr Geneeskd. 2010;154:A1574.

31. Smink AJ, van den Ende C, Vliet Vlieland TPM, Bijlsma JWJ, Swierstra BA, Kortland JA, et al. Stepped care bij artrose. Huisarts en Wetenschap. 2015;58(6):299-301.

32. Porcheret $\mathrm{M}$, Jordan $\mathrm{K}$, Croft $\mathrm{P}$. Treatment of knee pain in older adults in primary care: development of an evidence-based model of care. Rheumatology. 2007; 46(4):638-48. https://doi.org/10.1093/rheumatology/kel340.

33. van den Ende CM, Bierma-Zeinstra SM, Vlieland TP, Swierstra BA, Voorn TB, Dekker J. Conservative treatment of hip and knee osteoarthritis: a systematic, step-by-step treatment strategy. Ned Tijdschr Geneeskd. 2010;154:A1574.
34. Ruwaard D, Spreeuwenberg M, Kroese M, Steevens J, Ouwens M, Hilbink M, et al. Triple Aim and the application in the regional pioneer sites 'Population management' by VGZ and CZ. [Triple Aim en de toepassing in de regionale proeftuinen 'Populatiemanagement' van VGZ en CZ]. Maastricht University and Radboudumc; 2014.

35. Belo JN, Bierma-Zeinstra SMA, Raaijmakers AJ, Van der Wissel F, Opstelten W. Dutch clinical guidelines for nontraumatic knee complaints in adults in general practice. [NHG-Standaard Niet-traumatische knieproblemen bij volwassenen]. Huisarts en Wetenschap. 2008;51(5):229-40.

36. CBS Open data Statline [Dataset]. 2018. Available from: https://opendata.cbs. nl/statline/portal.html?_la=nl\&_catalog=CBS.

37. Savedoff WD, Gottret P. Governing mandatory health insurance. Washington, DC: World Bank; 2013.

38. Brekke KR, Nuscheler R, Straume OR. Gatekeeping in health care. J Health Econ. 2007;26(1):149-70. https://doi.org/10.1016/j.jhealeco.2006.04.004.

39. Kroneman $M$, Boerma W, van den Berg M, Groenewegen P, de Jong J, van Ginneken E. Netherlands: health system review. Health Syst Transit. 2016; 18(2):1-240

40. van Esch TEM, Brabers AEM, van Dijk CE, Gusdorf L, Groenewegen PP, de Jong JD. Increased cost sharing and changes in noncompliance with specialty referrals in the Netherlands. Health Policy. 2017;121(2):180-8.

41. Cadarette SM, Wong L. An introduction to health care administrative data. Can J Hosp Pharm. 2015;68(3):232-7.

42. Stone CA, Palmer JH, Saxby PJ, Devaraj VS. Reducing non-attendance at outpatient clinics. J R Soc Med. 1999;92(3):114-8.

43. Schut FT, Varkevisser M. Competition policy for health care provision in the Netherlands. Health Policy. 2017;121(2):126-33. https://doi.org/10.1016/j. healthpol.2016.11.002

44. Ranganathan P, Pramesh CS, Buyse M. Common pitfalls in statistical analysis: clinical versus statistical significance. Perspect Clin Res. 2015;6(3):169-70. https://doi.org/10.4103/2229-3485.159943.

45. Linsell L, Dawson J, Zondervan K, Rose P, Carr A, Randall T, et al. Population survey comparing older adults with hip versus knee pain in primary care. $\mathrm{Br}$ J Gen Pract. 2005;55(512):192-8.

46. Birrell F, Lunt M, Macfarlane GJ, Silman AJ. Defining hip pain for population studies. Ann Rheum Dis. 2005;64(1):95-8. https://doi.org/10.1136/ard.2003.018788.

47. Poulsen E, Overgaard S, Vestergaard JT, Christensen HW, Hartvigsen J. Pain distribution in primary care patients with hip osteoarthritis. Fam Pract. 2016; 33(6):601-6. https://doi.org/10.1093/fampra/cmw071.

48. Dabare C, Le Marshall K, Leung A, Page CJ, Choong PF, Lim KK. Differences in presentation, progression and rates of arthroplasty between hip and knee osteoarthritis: observations from an osteoarthritis cohort study-a clear role for conservative management. Int J Rheum Dis. 2017;20(10):1350-60. https://doi.org/10.1111/1756-185X.13083.

49. Ottenheijm RP, Hesselmans NJ, Kemper A, Moser A, de Bie RA, Dinant GJ, et al. GPS' perspectives on the diagnostic work-up in patients with shoulder pain: a qualitative study. J Eval Clin Pract. 2014;20(3):239-45. https://doi.org/ 10.1111/jep.12114.

50. Morgan B, Mullick S, Harper WM, Finlay DB. An audit of knee radiographs performed for general practitioners. Br J Radiol. 1997;70:256-60. https://doi. org/10.1259/bjr.70.831.9166050.

51. Baker R, Lecouturier J, Bond S. Explaining variation in GP referral rates for $X-$ rays for back pain. Implementation Science. 2006;1 (15). https://doi.org/10. 1186/1748-5908-1-15.

52. Little P, Dorward M, Warner G, Stephens K, Senior J, Moore M. Importance of patient pressure and perceived pressure and perceived medical need for investigations, referral, and prescribing in primary care: nested observational study. BMJ. 2004;328(7437):444. https://doi.org/10.1136/bmj.38013.644086.7C.

53. Epstein RM, Franks $P$, Shields CG, Meldrum SC, Miller KN, Campbell TL, et al. Patient-centered communication and diagnostic testing. Ann Fam Med. 2005;3(5):415-21. https://doi.org/10.1370/afm.348.

54. Rogers EM. Diffusion of innovations. 5th ed. New York: Free Press; 2003. 551 p.

55. Graham ID, Tetroe JM. Getting evidence into policy and practice: perspective of a health research funder. J Can Acad Child Adolesc Psychiatry. 2009;18(1):46-50.

56. Inacio MCS, Graves SE, Pratt NL, Roughead EE, Nemes S. Increase in Total joint Arthroplasty projected from 2014 to 2046 in Australia: a conservative local model with international implications. Clin Orthop Relat Res. 2017; 475(8):2130-7. https://doi.org/10.1007/s11999-017-5377-7.

57. Musila N, Underwood M, McCaskie AW, Black N, Clarke A, van der Meulen $J$ H. Referral recommendations for osteoarthritis of the knee incorporating 
patients' preferences. Fam Pract. 2011;28(1):68-74. https://doi.org/10.1093/ fampra/cmq066.

58. Cabana MD, Rand CS, Powe NR, Wu AW, Wilson MH, Abboud PA, et al. Why don't physicians follow clinical practice guidelines? A framework for improvement. JAMA. 1999;282(15):1458-65.

59. Steffensen FH, Sorensen HT, Olesen F. Impact of local evidence-based clinical guidelines--a Danish intervention study. Fam Pract. 1997;14(3):209-15.

60. Kristensen N, Nymann C, Konradsen H. Implementing research results in clinical practice- the experiences of healthcare professionals. BMC Health Serv Res. 2016;16:48. https://doi.org/10.1186/s12913-016-1292-y.

61. Howie JGR, Porter AMD, Forbes JF. Quality and the Use of Time in GeneralPractice - Widening the Discussion. BMJ. 1989;298(6679):1008-10. https:// doi.org/10.1136/bmj.298.6679.1008.

62. Orton PK, Gray DP. Factors influencing consultation length in generalfamily practice. Fam Pract. 2016;33(5):529-34. https://doi.org/10.1093/fampra/cmw056.

63. Wilson $\mathrm{A}$, Childs $\mathrm{S}$. The relationship between consultation length, process and outcomes in general practice: a systematic review. Br J Gen Pract. 2002; 52(485):1012-20

64. Wilson AD, Childs S, Goncalves-Bradley DC, Irving GJ. Interventions to increase or decrease the length of primary care physicians' consultation. Cochrane Database Syst Rev. 2016;8:CD003540. https://doi.org/10.1002/ 14651858.CD003540.pub3.

65. Pawson R, Greenhalgh J, Brennan C. Demand management for planned care: a realist synthesis. Southampton (UK): HS\&DR; 2016

66. Royal College of Physicians. Care closer to home: narrative report. London: RCP; 2012

67. Winpenny E, Miani C, Pitchforth E, Ball S, Nolte E, King S, et al. Outpatient services and primary care: scoping review, substudies and international comparisons. Southampton (UK): HS\&DR; 2016.

68. French SD, Green S, Buchbinder R, Barnes H. Interventions for improving the appropriate use of imaging in people with musculoskeletal conditions. Cochrane Database Syst Rev. 2010;1:CD006094. https://doi.org/10.1002/ 14651858.CD006094.pub2.

69. Hollingworth W, Todd CJ, King H, Males T, Dixon AK, Karia KR, et al. Primary care referrals for lumbar spine radiography: diagnostic yield and clinical guidelines. Br J Gen Pract. 2002;52(479):475-80.

70. Akbari A, Mayhew A, Al-Alawi MA, Grimshaw J, Winkens R, Glidewell E, et al. Interventions to improve outpatient referrals from primary care to secondary care. Cochrane Database Syst Rev. 2008:4:CD005471. https://doi. org/10.1002/14651858.CD005471.pub2.

71. Hyman J. The limitations of using insurance data for research. J Am Dent Assoc. 2015;146(5):283-5. https://doi.org/10.1016/j.adaj.2015.02.010.

72. Berwick DM, Nolan TW, Whittington J. The triple aim: care, health, and cost. Health Aff (Millwood). 2008;27(3):759-69. https://doi.org/10.1377/hlthaff.27.3.759.

73. Stiefel M, Nolan K. A guide to measuring the triple aim: population health, experience of care, and per capita cost. Institute for Healthcare Improvement: Cambridge, Massachusetts; 2012.

\section{Publisher's Note}

Springer Nature remains neutral with regard to jurisdictional claims in published maps and institutional affiliations.

Ready to submit your research? Choose BMC and benefit from:

- fast, convenient online submission

- thorough peer review by experienced researchers in your field

- rapid publication on acceptance

- support for research data, including large and complex data types

- gold Open Access which fosters wider collaboration and increased citations

- maximum visibility for your research: over $100 \mathrm{M}$ website views per year

At BMC, research is always in progress.

Learn more biomedcentral.com/submissions 